\title{
The Moderating Effect of Leader-Member Relationship on Introverted and Extroverted Personality Traits of Leaders and Organizational Citizenship Behaviors of Followers: An Empirical Study of IT Industry in Sri Lanka
}

\author{
W. A. M. Niranga \\ University of Kelaniya \\ M. P. P. Dharmadasa \\ University of Colombo
}

\begin{abstract}
This study focuses on investigating the relationship between personality and leadership supports the claim that individual differences may be the predictors of leadership effectiveness in contemporary organizations. Extended studies stress that 'Big-Five 'personality dimensions are related to leadership criteria and further identified introversion-extroversion as a key element of an individual personality. In general, the main differences between effective and less effective leaders are that, effective leaders make positive differences to themselves from their personality traits and the relationship building with followers. However, relatively few studies have tested how and why introvert and extrovert leaders' personality traits relate to follower behaviors. In addition, if so; the mechanisms through which a leader's personality traits relate to follower behaviors. Accordingly, the aims of the present study are to examine whether the introverted and extroverted personality traits of leaders affect the Organizational Citizenship Behavior (OCB) of followers and to examine the role of leader-member relationship as a moderator, in social exchange process. To advance the understanding of these, simple regression analysis and regression analysis with moderator effects were performed to test hypotheses with a sample size of 46 introvert managers and 50 extrovert managers as leaders and 92 and 100 subordinates as their followers respectively from IT industry in Sri Lanka. The study found that there is a
\end{abstract}

\section{Corresponding Author:}

Ms. W. A. M. Niranga, Lecturer, Department of Industrial Management, University of Kelaniya, Sri Lanka, E-mail: nirangam@kln.ac.lk 
positive direct effect of introverted personality traits of leaders and no negative direct effect of extroverted personality traits of leaders on organizational citizenship behavior of followers. Yet, leader-member relationship moderates the positive and negative relationships between introverted, extroverted personality traits of leaders and organizational citizenship behavior of followers. Present study makes several theoretical contributions to path-goal theory of leadership with the support from theory of trait leadership and big five model. Further, managerial contributions of the present study make IT firms successful through better selection of leaders based on personality traits which facilitates organizational citizenship behavior.

\section{Keywords}

Introverted personality traits, extroverted personality traits, OCB, Leadermember relationship, IT industry in Sri Lanka

\section{Introduction}

Research on relationship between personality traits and leadership; support the notion that different outcomes of individuals may be the predictors of leader behaviors (Hao and Yazdanifard, 2015). Therefore, it is vital for an organization to identify factors of its success, which can be measured from organizational performances and employee behaviors. Effective leader personality and extra role behavior of followers are the two main factors that have been regarded as key success factors for organizational performances. Contemporary organizations underline that employees should perform the work tasks and extra role behavior for the long-term survival of the organization (Neuman and Kickul, 1998). This can be defined as Organizational Citizenship Behavior at an individual's discretion that was not directly or explicitly rewarded but that will be taken as a fulfillment of the organization's objectives (Rauf, 2016 as cited in Organ, 1988).

Previous studies have indicated that each of the Big-Five personality traits namely conscientiousness, extraversion, agreeableness, openness to experience and emotional stability are related to leader criteria (Kahya and Sahin, 2018). Emphasizing introversion-extroversion as the main trait of big-five model, extroverts are found to be socially engaging, expressive, articulate and comfortable in group settings. In contrary, introverts seem quiet, low-key, deliberate, and less involved in the social world. Moreover, introverts prefer close relationships as they prefer more close interactions with small groups 
(Prakash, et al., 2016) whereas extroverts would like to address large groups which result shallow relationship among members (Hills and Argyle, 2001). Further, extroverts are more competitive and mainly focused on reward achievements whereas introverts are more corporative and directed to facilitate more relationships.

Yet, it is evident from contemporary organizational behaviors that they are struggling to create required OCB among employees due to the work tasks and primary objectives of the organization. In addition, it may not perform well in an environment which is stable, unchanging, and where centralized decisionmaking, written rules and procedures, and standardization of tasks are highly considered (De Grooth and Brownlee, 2006). To facilitate OCB, employees prefer more cooperativeness, close relationships and friendly working environment. As extroversion-introversion is the main personality trait according to the five-factor model, behaviors of extrovert leaders will not result OCB as they are more authoritative and dominant in nature. In contrast, cooperativeness and close interactions of introverts will result OCB among employees in work places, where no studies have been conducted to measure the direct relationship. Hence, this study focuses on 'whether introverted and extroverted personality traits of leaders influence the OCB of followers?' Leadership theories underline that leadership exists as a part of relationship between follower and the leader and is affected by mutual interaction (UusiKakkuri and Brandt, 2015). Asgari, Silong, Ahmad, \& Samah (2008) expressed leader-member relationship has become the foundation of a new era of managing a diversified workforce in globalized world today and developed organizational citizenship behaviour among employees. Therefore, it is evident that the relationship between personality traits of leaders and OCB of followers will be more strengthened or weakened due to the relationships among leaders and followers in contemporary organizational context. This can be theoretically rationalized by the social exchange theory and reciprocity theory which suggest employees who perceive leadership support (as seen through high quality leader-member relationship) should feel a sense of obligation to reciprocate by engaging in beneficial organizational actions. With this background, potential relationship between introverted personality traits of leaders and OCB of followers and extroverted personality traits of leaders and OCB of followers are moderated by leader-member relationship, which is not explored in the previous literature and is opened for more research. The present study contributes to research in this area. In support, it measures the impact of introverted and extroverted personality traits of leaders on OCB of followers and examines 
whether the leader-member relationship moderates the relationship between introverted personality traits and OCB of followers.

The remainder of this paper is organized as follows: Section two briefly reviews the literature pertaining to introverted personality traits of leaders, organizational citizenship behavior and leader-member relationship. In section three, research methodology is outlined. Section four presents the study's empirical results. The last section discusses the research findings, followed by a presentation of the research limitations and direction for future research.

\section{Literature Review}

Leader personality, which is a part of the leader traits, explains a minimum of thirty-one percent $(31 \%)$ of the variance in leadership effectiveness at large in an organization context (Derue, et al., 2011). The concept of personality has begun to attract a great deal of interest in behavioral ecology and human psychology. Personality differs from person to person (Nettle and Penke, 2010) based on the nature, environment, situation they face and the designation they hold in an organization. Moreover, leadership becomes the core area in most of the organizations, to achieve its objectives in resourceful and operative manner. Besides, leadership leads more positive outcomes of an organization such as job satisfaction, management of diversified workforce, organizational citizenship behavior and high employee commitment (Voegtlin, et al., 2012).

Apart from the studies that have focused on leadership effectiveness (Judge, et al., 2002; Derue, et al., 2011) several attempts were made to provide evidence on traits and behaviors of leaders (Kirkpatrick and Locke, 1991; Hogan, et al., 1994). According to Emanuelsson \& Lindqvist (2014) extroversion, selfconfidence, and courage are the traits that could potentially be linked with great leaders. Moreover, the study illustrated that, an introverted leader commonly uses a leader-member exchange leadership style leading to both engagement and empowerment, which will result organizational citizenship behavior of followers. Leader traits have a long and controversial history, where some literature supports for extroversion and some for introversion.

Introverts think carefully and analyze details before speaking, which is a key trait of a leader (Farrell, 2017). As Hautala (2006) expresses, introverts support for encouraging behavior and extroverts set targets and visions for the subordinates. This illustrates positive aspects of both introverts and extroverts. Moreover, managers who have more introvert traits, become exceedingly 
effective and efficient, especially when their jobs do not require much social interactions (Hudson and Ferguson, 2016). Besides, there are some instances where it is reported that introverts also have succeeded in leadership (Gio and Yazdanifard, 2015). According to Farrell (2017) extrovert leaders are better in carrying out the organizational projects where introvert leaders are ideal in planning process to gain sustainable competitive advantage. Even a very shy person should be able to lead a group to safety if a rival group was attacking them and he was the first to notice the danger (Vugt, 2006). Culturally, extroverts are seen as individuals who seek action, like working with others and are achievement-oriented (Clack, 2017). According to Farrell (2017) extroverts build up energy and ideas externally by developing social interactions. Judge, et al. (2002) explained that extraversion is strongly related to social leadership where leaders would like to address a large crowd. Further, they have illustrated that extraversion is the most important trait as both sociable and dominant people are more likely to assert themselves in group situations. Out of all leadership outcomes, one of the imperative leadership outcomes for an organization is 'Organizational Citizenship Behavior' which is significant to gain sustainable competitive advantage through human psychological engagement. With little research it is evident that OCB is facilitated from team performances, relationships between individuals, leader behaviors and personality traits (Neuman and Kickul, 1998; Elanain, 2007; Harper, 2015). This is a series of voluntary and optional actions that are not part of the person's official duties, but nonetheless done by him/her, and causes improvement in the functions and roles performed by the organization (Shoaeshargh and Dadashi, 2013 as cited in Alotaibi, 2009). However, a little research has carried on measuring the impact of leader personality on OCB of followers (Bernerth, et al., 2008).

It is evident that introverted personality type employees will be more likely to show a dutiful character, more likely to be altruism and obvious citizenship virtue compared to extrovert personality type employees (Harper, 2015). With the wide spectrum of identification of introvert leaders are passionate to give the freedom to employees while they are working for the organization which will lead to OCB as it is something discretionary and commitment towards what they do. Hills and Argyle (2001) express introverts experience high level of empathy with few special people with them which leads to trust and commitment as a part of OCB. Moreover, as Emmerik and Euwema (2007), introvert personalities are more sensitive for a good relationship with their team leaders and extroverts 
are less influenced by the relation with their leader when it comes to engagement in OCBs. Extroverted leaders are willing to dominate the context, as employees will take it as forceful reaction from leader and not contribute to OCB. Dominancy may discourage others to build up strong relationships with group members including the leader. Further, it may discourage others to commit more on mutual trust among group members that will cause to reduce the performances in the long run as there is no autonomy for others to work leisurely. As Power (2017) points out, even though extroverts prefer more interactions, they can quickly be aggressive when trying to impress others or earn their respect through over commitment. Further, Grant, et al. (2011) illustrated that although extraverted leadership enhances group performance when employees are passive, this effect reverses when employees are proactive; because extraverted leaders are less receptive to proactivity. Moreover, extroverted leaders may not be successful in organizational performances where the leader is too busy socializing with all levels of the working environment and acting upon them. Farrell (2017) brought up the failures of extroverted leaders as they are arrogant, bossy and self- centered. Perception of leader supportiveness ranked as the highest antecedent on OCB out of other leadership behaviours (Podsakoff, et al., 2000). Therefore, the below hypotheses were developed to investigate the direct effect between the introverted and extroverted personality traits of leaders and OCB of followers.

Hypothesis 1a: Introverted personality traits of leaders positively affect the OCB of followers.

Hypothesis 1b: Extroverted personality traits of leaders negatively affect the OCB of followers.

High-quality supervisor-subordinate relationships were positively related to a desire to help others and be accepted by them, as well as a positive regard for the organization (Connell, 2005). Conversely, extroverts do not develop a longterm employee organizational association that emphasizes trust, mutuality and shared aspirations (Neuman and Kickul, 1998) even though they get to know each other quickly (Prakash, et al., 2016). This study further illustrated that extroverts do not concentrate on mutual trust and an open-ended commitment, which represents from the conventional relationship between an employee and an organization. Moreover, extroverts are more competitive and mainly focused on reward achievements whereas introverts are more corporative and directive to facilitate more relationships. Similarly, supervisor-subordinate relationships characterized by high levels of trust, support, liking, and attention 
MODERATING EFFECT OF LEADER-MEMBER RELATIONSHIP ON THE RELATIONSHIP BETWEEN INTROVERTED AND EXTROVERTED PERSONALITY TRAITS OF LEADERS AND ORGANIZATIONAL CITIZENSHIP BEHAVIOR OF FOLLOWERS

were also associated with increased OCB. As per Hui, Lee and Rousseau (2004) citizenship behavior has identified as people-oriented activity where they focus on more citizenship behavior through leader-member relationship. Moreover, the trust between leader and the followers will be another reason for a better relationship to last (Konovsky and Pugh, 1994). Further, Dulebohn, Boommer, Liden, Brouer, and Ferris (2012) identified high leader-member relationship increasingly engender feelings of mutual obligation and reciprocity. Moreover, Konovsky and Pugh (1994) illustrated that supervisors' fair treatment on employees and trust lead to citizenship behaviour in organization. This can be further theoretically rationalized through the social exchange theory. Therefore, it is worthwhile to understand how leader-member relationship effects on different personalities of leaders and OCB of followers. Based on these, the below hypotheses were developed to measure the moderating effect of leadermember relationship on personality traits of leaders and OCB of followers.

Hypothesis 2a: Relationship between introverted personality traits of leaders and OCB of followers is moderated by Leader-Member relationship.

Hypothesis 2b: Relationship between extroverted personality traits of leaders and OCB of followers is moderated by Leader-Member relationship.

\section{Research Methodology}

This study was conducted on self-administered survey strategy and followed mono method with the support of quantitative method as per the statistical generalization is the preferred method to measure causal relationships that measure the impact of introverted and extroverted personality traits of leaders and organizational citizenship behavior of followers. Due to the nature of this study, cross-sectional time horizon has been selected as the preferable way where the data collection can be carried in one given time period. Managers and subordinates have been selected as dyads to measure the causality of variables.

Population, Sample and Data Collection: The population of this study is unjustifiable as there is no proven document available in Sri Lanka to justify

number of managers and subordinates working in different organizations all over the country. 
The sample of this study consisted of 46 introvert leaders, 50 extrovert leaders and 92 and 100 followers of these leaders respectively from Information Technology industry in Sri Lanka. This sample was chosen, due to hierarchical structure and the responsibilities of leader-follower dyadic relations in the selected IT industry, and easy identification and reliable testing of the leaderfollower relationship. The self-administered questionnaires were delivered based on survey strategy to managers to measure introverted and extroverted personality traits of leaders and subordinates to measure OCB and leadermember relationship.

Variables and model: Organizational Citizenship Behavior is the dependent variable of the present study. This was measured using five dimensions: altruism, civic virtue, conscientiousness, courtesy and civic virtue using 24-items of OCB measurement scale developed by Podsakoff and Mackenzie (1990). The independent variable introverted and extroverted personality traits of leaders was measured using NEO PI-R scale of personality developed by Costa and McCrae (1989). This study used one moderator variable; leader-member relationship which was measured using 7-items LMX reported by Scandura and Graen (1984). The working definitions of the constructs are presented in table 1 .

Table 1: Working Definitions of the Constructs

\begin{tabular}{llll}
\hline \multicolumn{1}{c}{ Construct } & Working Definition & \multicolumn{1}{c}{ Indicator } & $\begin{array}{c}\text { Measurement } \\
\text { Scale }\end{array}$ \\
\hline Introverted & Quiet, low-key, & - Warmth & NEO PI-R scale \\
Personality & deliberate, and less & & of personality by \\
Traits & involved in the & -Gregariousness/ & Costa and \\
& social world, prefer & Sociability & McCrae (1989) \\
& more close & & (5-point Likert \\
& interactions with & -Assertiveness- & Scale- 5 as the \\
& small groups, more & Forcefulness & as the low score) \\
& corporative and & & \\
directing to facilitate & -Activity & \\
more relationships. & & \\
Personality & Socially engaging, & -Excitement Seeking & \\
Traits & expressive, & \\
& articulate, & & \\
& comfortable in group & -Positive Emotions & \\
& settings, shallow & & \\
& relationship among & & \\
& members, more & & \\
\hline
\end{tabular}




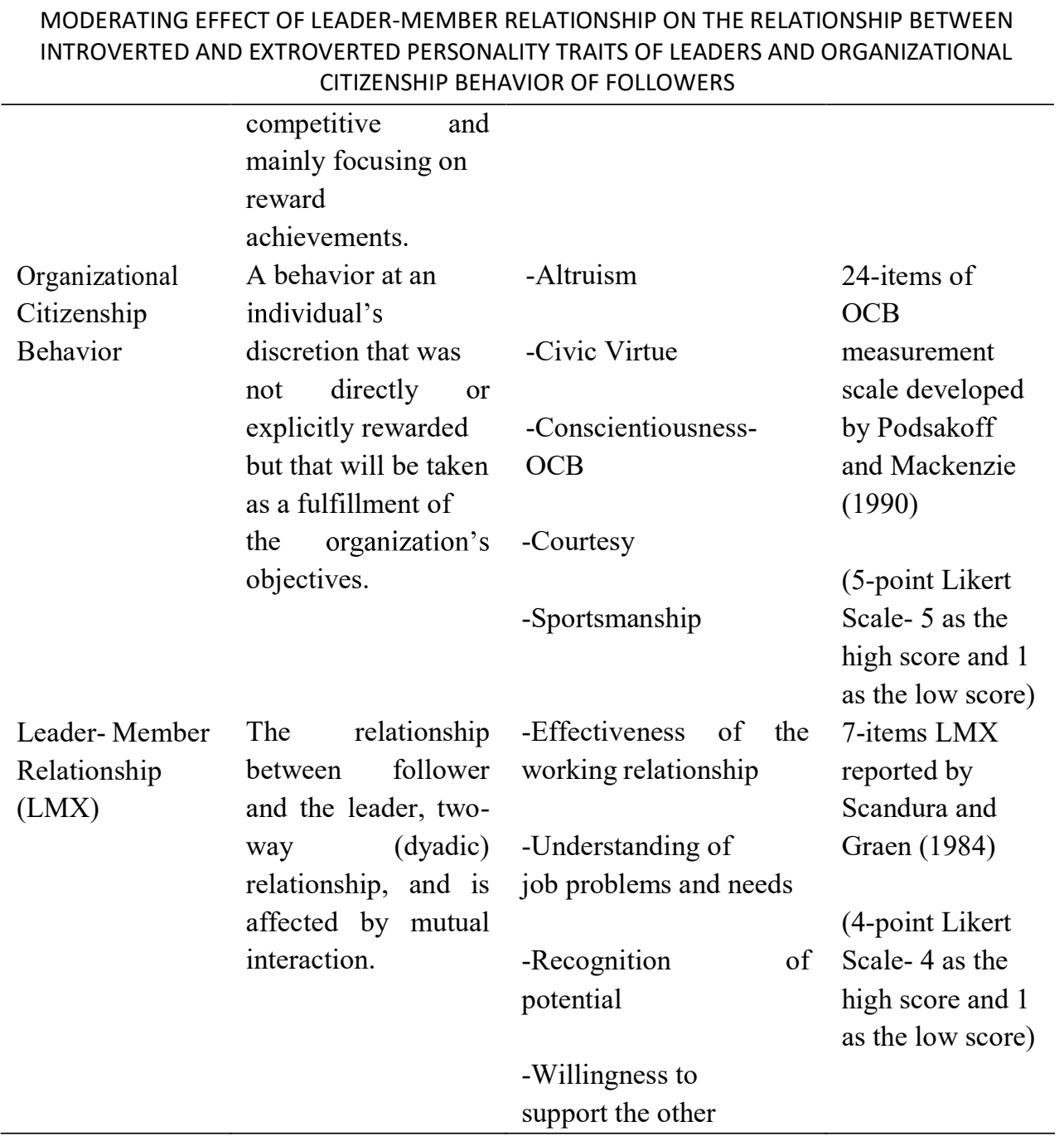

Source:(Big-five personality dimensions; Shoaeshargh and Dadashi, 2013 as cited in Alotaibi, 2009; Uusi-Kakkuriand Brandt, 2015)

Data Analytical Techniques: In this study, all five steps of data screening were carried out before analyzing the data. The steps include assessing the accuracy and completeness, testing for parametric assumptions, testing for validity and reliability, testing for association and testing for multicollinearity and common method variance. Then, the data analysis has been presented from descriptive statistics and correlations of the variables. Later, simple linear regression analysis and the moderator testing (Moderator Multiple Regression by David A. Kenny) have been used to measure the direct effect and moderating effect. 


\section{Results and Findings}

First, accuracy and completeness of data were checked under the data screening. Any outlier was not identified in the data sheet and data accuracy was up to the standard. Then, Parametric assumptions namely; normality, linearity, homoscedasticity and homogeneity of error variance, and independence were tested and fulfilled the requirements accordingly. Then, the validity was tested in content validity, criterion-related validity and construct validity. All the validities were met in the present study. Validity was measured based on the assumption of Cronbach's alpha value and found all the variables values are $>$ 0.7. Then, the descriptive statistics and the correlations of the variables were presented below.

Table 2 shows the descriptive statistics and correlations of the variables.

Table 2: Means, Standard deviations, and Pearson correlation coefficients of variables

\begin{tabular}{lllllll}
\hline & Mean & SD & LMX-I & LMX-E & OCB-I & OCB-E \\
\hline IPT & 3.1660 & 0.0799 & $0.583^{* *}$ & - & $0.344^{* *}$ & - \\
EPT & 3.4926 & 0.1233 & - & 0.047 & - & $0.231^{* *}$ \\
LMX-I & 3.2986 & 0.4538 & - & - & $0.433^{* *}$ & - \\
LMX-E & 3.0267 & 0.5483 & - & - & $0.551^{* *}$ & - \\
OCB-I & 3.8333 & 0.3948 & - & - & - & - \\
OCB-E & 3.6149 & 0.2951 & - & - & - & - \\
\hline
\end{tabular}

${ }^{* *}$ Correlation is significant at the 0.01 level (2-tailed)

Note. (1) Between .1-.3: Small Effect. (2) Between .3-.5: Medium Effect. (3) Above .5: Large Effect

IPT- Introverted personality traits, EPT- Extroverted personality traits, OCB-I/E Organizational Citizenship Behaviour-Introverts/Extroverts, LMX-I/E LeaderMember Exchange/Relationship-Introverts/Extroverts

An examination of correlations revealed a positive association among the variables. Overall, the direct patterns and one of the moderating effects of the correlations were much like the expected results. Yet, moderating effect is not so strong with the direct relationship with extroverted personality traits of leaders and organizational citizenship behavior of followers.

The results of the regression used to test the hypotheses of introvert and extrovert leaders are shown in table 3 and 4. 
MODERATING EFFECT OF LEADER-MEMBER RELATIONSHIP ON THE RELATIONSHIP BETWEEN INTROVERTED AND EXTROVERTED PERSONALITY TRAITS OF LEADERS AND ORGANIZATIONAL CITIZENSHIP BEHAVIOR OF FOLLOWERS

Table 3: Regression results for Introverted personality traits, $\mathrm{OCB}$ and Leader-Member Relationship

\begin{tabular}{lccc}
\hline & Model 1 & Model 2 & Model 3 \\
\hline Intercept & -1.555 & 3.833 & 3.789 \\
& $(-1.267)$ & $(130.645)$ & $(155.028)$ \\
Beta Value & $0.344^{*}$ & $0.130^{* *}$ & $0.120^{* *}$ \\
& $(4.392)$ & $(1.421)$ & $(1.331)$ \\
LMX & & $0.367^{*}$ & $0.388^{*}$ \\
& & $(3.999)$ & $(4.305)$ \\
Intro traits X LMX & & & $0.199^{*}$ \\
& & & $(2.719)$ \\
$\mathrm{R}$ & 0.344 & 0.455 & 0.497 \\
$\mathrm{R}^{2}$ & 0.118 & 0.207 & 0.247 \\
Adjusted $\mathrm{R}^{2}$ & $0.112^{*}$ & $0.196^{*}$ & $0.231^{*}$ \\
$\mathrm{R}^{2}$ change & 0.118 & 0.207 & 0.247 \\
F change & $19.290^{*}$ & $18.648^{*}$ & $15.453^{*}$ \\
\hline
\end{tabular}

Source: Survey data

Dependent variable: OCB

Note: Data are standardized regression weights. Intro traits $=$ Introverted Traits of leaders; LMX = Leader-Member Exchange/Relationship ${ }^{*} \mathrm{p}<.05 .{ }^{* *} \mathrm{p}<.01{ }^{* * *} \mathrm{p}<.001$.

These results show that introverted personality traits of leaders had a positive relationship with OCB of followers $(\beta=0.344, p \leq 0.05)$, significant at the ninety-five percent (95\%) level. This finding is consistent with evidence from previous studies (Emmerik and Euwema, 2007; Harper, 2015; Farrell, 2017). Further, relationship between introverted personality traits of leaders and OCB of followers is moderated by Leader-Member relationship $(\beta=0.130, p \leq$ 0.05 ) as suggested and it became more prominent with the interaction effect ( $\beta$ $=0.120, p \leq 0.05)$. Adjusted $\mathrm{R}^{2}$ value of 0.231 represents the overall impact of introverted personality traits of leaders with interaction effect of leader-member relationship quality on OCB of followers $(F=15.453, p \leq 0.05)$. Based on the results, there is a synergistic effect from leader-member relationship moderation variable to introverted personality traits of leaders and OCB of followers. It represents both introverted personality traits of leaders and leader-member relationship affect the OCB of followers in the same direction and together they produce a strong relationship than additive effect on OCB of followers. 
Figure 1: Synergistic Effect

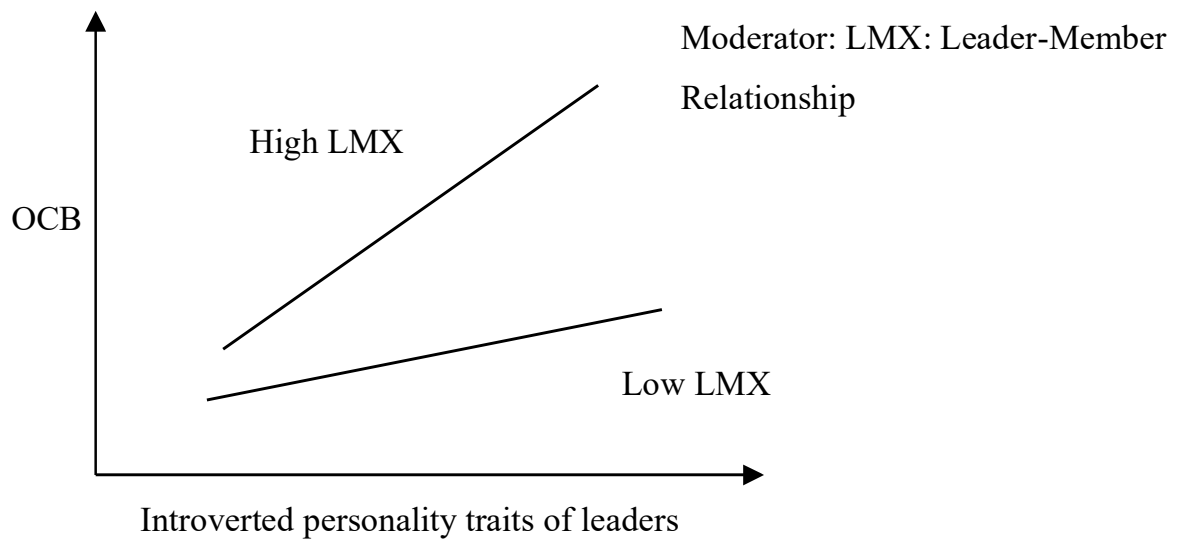

Table 4: Regression results for Extroverted personality traits, OCB and Leader-Member Relationship

\begin{tabular}{lccc}
\hline & Model 1 & Model 2 & Model 3 \\
\hline Intercept & 1.682 & 2.734 & 3.618 \\
& $(2.714)$ & $(26.706)$ & $(204.670)$ \\
Beta Value & $0.231^{*}$ & $0.206^{*}$ & $0.185^{*}$ \\
& $(3.122)$ & $(3.325)$ & $(3.067)$ \\
LMX & & $0.541^{*}$ & $0.474^{*}$ \\
& & $(8.744)$ & $(7.480)$ \\
Extro traits & $\mathrm{X}$ & & $-0.215^{*}$ \\
LMX & & & $(-3.374)$ \\
$\mathrm{R}$ & & & 0.622 \\
$\mathrm{R}^{2}$ & 0.231 & 0.588 & 0.386 \\
Adjusted $\mathrm{R}^{2}$ & 0.054 & 0.345 & $0.376^{*}$ \\
$\mathrm{R}^{2}$ change & $0.048^{*}$ & $0.338^{*}$ & 0.386 \\
F change & 0.054 & 0.345 & $35.780^{*}$ \\
\hline
\end{tabular}

Source: Survey data

Dependent variable: OCB

Note: Data are standardized regression weights. Extro traits $=$ Extroverted Traits of leaders; LMX= Leader-Member Exchange/ Relationship

${ }^{*} \mathrm{p}<.05 .{ }^{* *} \mathrm{p}<.01 .{ }^{* * *} \mathrm{p}<.001$ 
MODERATING EFFECT OF LEADER-MEMBER RELATIONSHIP ON THE RELATIONSHIP BETWEEN INTROVERTED AND EXTROVERTED PERSONALITY TRAITS OF LEADERS AND ORGANIZATIONAL CITIZENSHIP BEHAVIOR OF FOLLOWERS

These results show that extroverted personality traits of leaders had a positive relationship with OCB of followers $(\beta=0.231, p \leq 0.05)$ which is not supported for hypothesis as suggested. This finding is consistent with evidence from previous studies (Neuman and Kickul, 1998 as cited in Krebs, 1970; Chiaburu, et al., 2011). Yet, with regards to Information Technology industry firms in Sri Lanka, the results of the moderation effect is significant at $95 \%$ confidence level. Adjusted $\mathrm{R}^{2}(0.376)$ represents the overall impact of extroverted personality traits of leaders with interaction effect of leader-member relationship quality on $\mathrm{OCB}$ of followers $(\mathrm{F}=35.780, \mathrm{p} \leq 0.05)$. Based on the results, there is an Antagonistic effect from leader-member relationship moderation variable to introverted personality traits of leaders and OCB of followers. It represents both extroverted personality traits of leaders and leadermember relationship predict OCB in the same direction. But they each weaken each other. The importance of extroverted personality traits of leaders is weakened the presence of the leader-member relationship for OCB of followers.

\section{Figure 2: Antagonistic Effect}

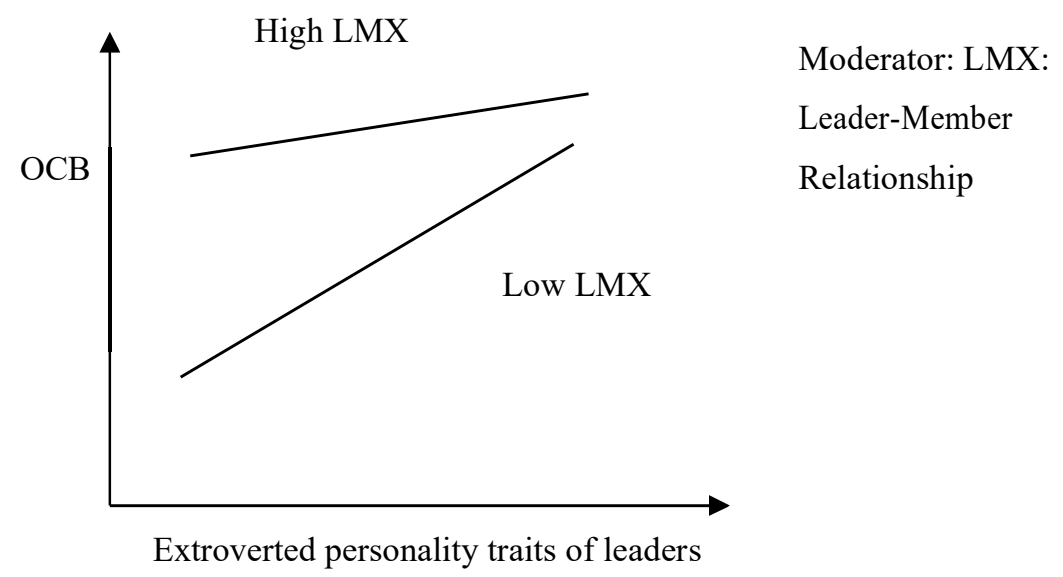

\section{Discussion}

This study not only replicates but also extends previous research on the direct effect and moderating effect on leader-member relationship of the relationship between the personality traits of leaders and OCB of followers. In answering research questions, the present study focuses on introverted and extroverted personality traits of leaders of IT industry in Sri Lanka. First, the results of this 
study replicate previous findings (Emmerik and Euwema, 2007; Grant, et al., 2011; Harper, 2015; Ahmed and Khan, 2016) establishing positive direct effect of introverted personality traits of leaders on OCB of followers. Similarly, the results of this are in line with the findings of the previous studies (Buchanan, 1998; Neuman and Kickul, 1998; Owen , et al., 2000; Hills and Argyle, 2001; Asgari , et al., 2008; Prakash, et al., 2016) and indicate that the leader-member relationship is a significant determinant of positive direct effect of introverted personality traits of leaders and negative direct effect of extroverted personality traits of leaders on OCB of followers. Yet, the negative direct impact on extroverted personality traits of leaders and OCB was not statistically significant in the present study. That may be the operating environment, situation, culture or habits which enhance positive and negative impact on leadership personalities (Baldwin, 2014). As Mooney (2018) states, the nature of a company's culture influences; if there is a strong culture employee will be motivated and welltrained. IT professionals include dependability and the ability to adapt to a changing work environment, such as the need to come in on weekends to address critical systems issues (Long, n.d.). Further, individuals should also feel comfortable working as part of a larger team to complete tasks rather than isolation. Further, as Leonard (2018) expresses, type of the work task affects the leadership behaviours of individuals. As per the IT professionals in Sri Lanka, it is evident that they have to change their leadership traits based on the task accomplishment.

Importantly, the present study extends previous research by examining the moderating role of leader-member relationship between the direct relationship. As hypothesized, the results of the present study supported that leader-member relationship moderated the relationship between introverted and extroverted personality traits of leaders and OCB of followers. First, it provides empirical support for leader-member relationship regarding the tendency of high-quality relationship between manager/leader and subordinate/follower to enhance organizational citizenship behaviour of followers. This enhancement of follower performance is important as previous researches have indicated that introverted personality traits of leaders and leader-member relationship can contribute to effective outcomes of an organization (Hautala, 2006; Bernerth, et al., 2008). Second, findings of this study also provide empirical support for the extrovert's relationship behaviour suggested by Hills and Argyle (2001) and Neuman and Kickul (1998). The findings suggest that extroverted leader personality trait is not a foundational leader characteristic for the OCB of followers. Social exchange relationships, on the other hand, have an impact on the maintenance of 
MODERATING EFFECT OF LEADER-MEMBER RELATIONSHIP ON THE RELATIONSHIP BETWEEN INTROVERTED AND EXTROVERTED PERSONALITY TRAITS OF LEADERS AND ORGANIZATIONAL CITIZENSHIP BEHAVIOR OF FOLLOWERS

the power and solidarity depending on its long-term relationship and mutual trust.

\section{Conclusion}

In conclusion, despite the importance of leadership characteristics in organizations, this research examines the promising mechanisms through which leader personality influences followers' effective performance, which has been lacking. The present study makes an important contribution by examining how leader personality traits (introverted and extroverted) influence follower attitudes and behaviors by displaying the importance of leader-member relationship. Hence, this study provides a better understanding of how leader personality influences follower organizational citizenship behavior.

Theoretically, the findings of this study provide understandings for two bodies of work. First, the direct effect of introverted personality traits of leaders and OCB of followers was supported which rationalized from path-goal theory with the support of theory of trait leadership and five factor model of personality. It further, reveals that leader behavior is important for the follower motivation and goal achievement identified by previous research (House and Mitchell, 1975; Ng, et al., 2008; Malik, et al., 2014) and OCB was generated. However, direct effect of extroverted personality traits of leaders and OCB of followers is not supported with the theoretical argument. Motivated employees will not automatically engage in $\mathrm{OCB}$, unless the organization ensures the presence of job satisfaction, job involvement, psychological empowerment, perceived organizational support, employee engagement and organizational justice (Ahmed and Khan, 2016).Second, the moderating effect of leadermember relationship revealed by this study and previous research (Harris, et al., 2007; Uusi-Kakkuri and Brandt, 2015) supports the theoretical argument and make contributions to the social exchange theory.

\section{Limitations and Avenue for Future Research}

Selection of participants in one industry at a given period was a limitation of this present study. Nevertheless, future research might consider a longitudinal research design examining perceptions of introverted and extroverted personality traits, OCB and leader-member relationship multiple times over a long period of time. The present study encourages future researchers to carry out the same study again with the change of research design to a qualitative research as respondents have not given the assured answers based on 
questionnaire method. The researchers would be able to observe and understand reactions of respondents if they can conduct the study through interview method as the data collection tool. There will be more interesting answers with the close monitoring methods between the researcher and the respondent.

\section{References}

Ahmed, S. W., \& Khan, T. (2016). Does motivation lead to organzational citizenship behaviour?- A Theoretical review. Global Journal of Management and Business Research: A Administration and Management, $16(7), 42-49$.

Asgiri, A., Silong, A. D., Ahmad, A., \& Samah, B. A. (2008). The relationship between leader-member exchange, organizational inflexibility, perceived organizational support, interactional justice and organizational citizenship behaviour. African Journal of Business Management, 2(8), 138-145.

Baldwin, S. (2014, September 4). Top Five Factors that Influence Leadership Behaviour. Retrieved from leadadvantage web site: http://leadadvantageinc.com/top-five-factors-influence-leadershipbehaviour/

Bernerth, J. B., Armenakis, A. A., Feild, H. S., Giles, W. F., \& Walker, H. J. (2008). The Influnce of personality differences between subordinates and supervisors on perceptions of LMX. Group \& Organizational Management, $33(2), 216-240$.

Buchanan, L. B. (1998). The impact of big five personality characteristics on group cohesion and creative task performance. Blacksburg, Virginia: Faculty of Virginia Polytechnic Institute and State University.

Chiaburu, D. S. et al., 2011. The Five-Factor Model of Personality Traits and Organizational Citizenship Behaviours: A Meta-Analysis. Journal of Applied Psychology, 96(6), pp. 1140-1166.

Clack, L. A., 2017. Examination of Leadership and Personality Traits on the Effectiveness of Professional Communication in Healthcare. Journal of Healthcare Communications, 2(2), pp. 1-4. 
MODERATING EFFECT OF LEADER-MEMBER RELATIONSHIP ON THE RELATIONSHIP BETWEEN INTROVERTED AND EXTROVERTED PERSONALITY TRAITS OF LEADERS AND ORGANIZATIONAL CITIZENSHIP BEHAVIOR OF FOLLOWERS

Connell, P. W. (2005). Transformational leadership, leader-member exchange $(L M X)$, and $O C B$ : The role of motives. University of South Florida.

DeGrooth, T., \& Brownlee, A. L. (2006). Effect of department structures on the organizational citizenship behaviour-department effectiveness relationship. Journal of Business Research, 59(10-11), 1116-1123.

Derue, D. S., Hahrgang, J. D., Wellman, N., \& Humphrey, S. E. (2011). Trait and behavioural theories of leadership: An integration and meta-analytic test of their relative validity. Personnel Psychology, 64(1), 7-52.

Elanain, H. A. (2007). Relationship between personality and organizational citizenship behaviour: Does personality influence employee ctizenship? International Review of Business Research papers, 3(4), 31-43.

Emanuelsson, A., \& Lindqvist, S. (2014). Leadership of Introverts- An exploratory study of how introvert managers lead in Sweden. Sweden: Bleking Institute of Technology, School of Management.

Emmerik, H. v., \& Euwema, M. C. (2007). Who is offering a helping hand?: Associations between personality and $\mathrm{OCBs}$, and the moderating role of team leader effectiveness . Journal of Managerial Psychology, 22(6), 530548.

Farrell, M. (2017). Leadership Reflections: Extrovert and Introvert Leaders. Journal of Library Administration, 57(4), 436-443.

Gio , T. H., \& Yazdanifard , R. (2015). The Unconventional Leadership of Corporate Leaders in the 21st Century. Global Journal of Management and Business Research, 15(4), 77-81.

Grant, A. M., Gino , F., \& Hofma, D. A. (2011). Reversing the Extraverted Leadership Advantage: The Role of Employee Proactivity. Academy of Management, 54(3), 528-550.

Hao , M. J., \& Yazdanifard, R. (2015). How Effective Leadership can Facilitate Change in Organizations through Improvement and Innovation. Global Journal of management and Business Research: A Administration and Management, 15(9), 1-7. 
Harper , P. J. (2015, February). Exploring forms of organizational citizenship behaviours (OCB): antecedents and outcomes. Journal of Management and Marketing Research, 36(1), 1-16.

Harris, K. J., Harris , R. B., \& Eplion, D. M. (2007). Personality, LeaderMember Exchanges, and Work Outcomes. Southeast: Institute of Behavioural and Applied Management.

Hautala, T. M. (2006). Leaders' personality and its impact on the subordinates' ecpectations of leadership. Psychological type and culture-East \& West: A multicultural research conference, (pp. 6-8). Honolulu, Hawaii.

Hills, P., \& Argyle, M. (2001). Happiness, introversion-extroversion and happy introverts. Personality and Individual Differences, 30(4), 595-608.

Hogan, R., Curphy, G. J., \& Hogan, J. (1994). What we know about leadership. Effectiveness and personality, 49(6), 493-504.

House, R. J., \& Mitchell, T. R. (1975). Path-Goal Theory of Leadership. Toronto: Faculty of Management Studies, University of Toronto.

Hui, C., Lee , C., \& Rousseau, D. M. (2004). Employment Relationships in China: Do Workers Relate to the Organization or to People? Organization Science, 15(2), 232-240.

Judge, T. A., Bono, J. E., Ilies, R., \& Gerhardt, M. W. (2002). Personality and Leadership: A qualitative and quantitative review. Journal of Applied Psychology, 87(4), 765-780. doi:10.1037/0021-9010.87.4.765.

Kahya , M. and Sahin, F., 2018. The effect of leader personality on follower behaviour: The mediating role of leader-member exchange. Leadership and organizational Development Journal, 39(1), pp. 14-33.

Kirkpatrick, S. A., \& Locke, E. A. (1991). Leadership: do traits matter? Academy of Managment Executive, 5(2), 48-60.

Konovsky, M. A., \& Pugh, S. D. (1994 ). Citizenship Behaviour and Social Exchange. The Academy of Management Journal, 37(3), 656-669.

Leonard, K. (n.d.). Factors Influencing Leadership Styles. Retrieved April 23, 2018, from Chron website: http://smallbusiness.chron.com/factorsinfluencing-leadership-styles-45181.html 
MODERATING EFFECT OF LEADER-MEMBER RELATIONSHIP ON THE RELATIONSHIP BETWEEN INTROVERTED AND EXTROVERTED PERSONALITY TRAITS OF LEADERS AND ORGANIZATIONAL CITIZENSHIP BEHAVIOR OF FOLLOWERS

Long, N. (n.d.). Personalities That Do Well in the IT Industry. Retrieved April 24, 2018, from Chron Web site: http://smallbusiness.chron.com/personalities-well-industry-10591.html

Malik, S. H., Aziz, S., \& Hassan, H. (2014). Leadership behaviour and acceptance of leaders by subordinates: Application of path goal theory in Telecom sector. International Journal of Trade, Economics and Finance, 5(2), 170-175.

Mooney, L. (n.d.). Factors Influencing Leadership Styles. Retrieved April 5, 2018, from azcentral.com website: https://yourbusiness.azcentral.com/factors-influencing-leadership-styles9263.html

Nettle , D., \& Penke , L. (2010). Personality: bridging the literatures from human psychology and behavioural ecology. Philosophical Transactions: Biological Sciences, 365(1560), 4043-4050 .

Neuman, G. A., \& Kickul, J. R. (1998). Organizational Citizenship Behaviours: Achievement Orientation and Personality. Journal of Business and Psychology, 13(2), 263-279.

Ng , K. Y., Ang, S. and Chan, K. Y., 2008. Personality and leader effectiveness: A moderated mediation model of leadership self-efficacy, job demands and job autonomy. Journal of Applied Psychology, 93(4), pp. 733743.

Owen , F. A., Pappalardo , S. J., \& Sales, C. A. (2000). Organizational Citizenship Behaviour: Proposal for a New Dimension in Counsellor Education . Canadian Journal of Counselling, 34(2), 98-110.

Podsakoff, P. M., MacKenzie , S. B., Paine, J. B., \& Bachrach , D. G. (2000). Organizational Citizenship Behaviours: A Critical Review of the Theoretical and Empirical Literature and Suggestions for Future Research. Journal of Management, 26(3), 513-563.

Power, R. (2017, December 12). People: inc. Retrieved April 23, 2018, from inc Web Site: https://www.inc.com/rhett-power/effective-managementextroverts-vs-introverts.html 
Prakash, S., Singh, A., \& Yadav, S. K. (2016). Personality (Introverts, and Extrovert) and Professional commitment: effect among B.Ed teacher educator students. The International Journal of Indian Psychology, 3(2), 2349-3429

Rauf, A. (2016). Two sides of the same coin: Harmful or Helpful? A critical review of the consequences of organizational citizenship behavior. International Journal of Business and Management Review, 4(2), 60-77.

Shoaeshargh, F., \& Dadashi, M. A. (2013). Analyzing the relationship between personality type (extrovert-introvert) and organizational citizenship behaviour in Shoa e Shargh Concrete Company. Technical journal of Engineering and Applied Sciences, 3(18), 2159-2162.

Uusi-Kakkuri, P., \& Brandt, T. (2015). Preferred leadership behaviour by different personalities. International jornal of Business and Globalization, 15(4), 461-474.

Voegtlin, C., Patzer , M., \& Scherer, A. G. (2012). Responsible Leadership in Global Business: A New Approach to Leadership and Its MultiLevel outcomes. Journal of Business Ethics, 105(1), 1-16.

Vugt, M. V. (2006). Evolutionary Origins of Leadership and Followership. Personality and Social Psychology Review, 10(4), 354-371. 